\title{
Coexistence of Tuberculosis and Mammary Carcinoma in a Goat
}

\author{
H Quintas ${ }^{1,2}$, N Alegria ${ }^{2}$, A Mendonça ${ }^{3}$, A Botelho ${ }^{4}$, A Alves ${ }^{2}$ and I Pires ${ }^{2}$ \\ ${ }^{1}$ ESA, Polytechnic Institute of Bragança, Bragança, Portugal; ${ }^{2}$ CECAV, Department of Veterinary Sciences, University of Trás-os-Montes and Alto \\ Douro, Vila Real, Portugal; ${ }^{3}$ Centro de Investigação Montanha, ESA, Polvtechnic Institute of Braganca, Braganca, Portugal; ${ }^{4}$ INIAV, I.P. - \\ Instituto Nacional de Investigação Agrária e Veterinária, IP, Unidade Estratégica de Investigação e Serviços de Produção e Saúde Animal, Lisbon, \\ Portugal
}

\section{Contents}

Synchronic occurrence of tuberculosis mastitis and mammary cancer is rare in humans and, to the best of our knowledge, not reported in domestic animals. Here, we present a case of a female adult goat of Serrana breed with simultaneous occurrence of a granulomatous mastitis, due to Mycobacterium caprae, and a mammary carcinoma. Both pathological conditions are rare in goats and should be included in differential diagnosis of mammary lesions.

\section{Introduction}

Mammary tumours tend to be common in domestic animals, such as dogs and cats, but are rarely found in farm animals, such as goats, which have a low prevalence of mammary neoplasia. Only a few cases of the latter are described in the veterinary literature (Cooke and Merrall 1992; Wooldridge et al. 1999; Löhr 2013).

Tuberculosis was, in the past, considered rare in goats. However, nowadays caprine tuberculosis is regarded as an important disease in many countries, including Portugal (Quintas et al. 2010). Caprine tuberculosis is mainly caused by Mycobacterium caprae, but M. bovis can occasionally be isolated from goats (Gutierrez et al. 1995; Aranaz et al. 2003). Infection with either pathogen represents a serious concern due to the economic losses involved and to the possible spread to bovine herds. Furthermore, it represents a potential source of infection for humans through unpasteurized dairy products and direct contact (Gutierrez et al. 1997; Kubica et al. 2003).

In humans, the association of tuberculosis and cancer has been recorded in different types of tumours, such as lymphoma, renal carcinoma and meningioma (TenaSuck et al. 2010; Inoue et al. 2012; Mani et al. 2013). However, the coexistence of cancer and tuberculosis in the mammary gland is uncommon in man, and only a few cases have been reported in the literature. In domestic animals, to the best of our knowledge, there have been no reports of a simultaneous occurrence of tuberculosis and mammary carcinoma in the mammary gland.

\section{Case History}

In this report, a rare case of simultaneous occurrence of tuberculosis and carcinoma is described in a mammary gland of a 7-year-old female goat of a native Portuguese breed - Serrana. The case was detected during an outbreak of caprine tuberculosis.

At clinical examination, the animal presented fever, weakness and cough. The udder was enlarged and firm.
The doe was subsequently slaughtered and post mortem examination revealed moderately enlarged mediastinal lymph nodes and yellowish/white caseous or caseocalcareous lesions in the lungs. Similar lesions were observed in the liver, spleen and mesentery. The mammary gland presented yellowish caseous multifocal areas in the parenchyma, ranging from 0.5 to $1.5 \mathrm{~cm}$ (Fig. 1). The supramammary lymph node was enlarged with caseous granulomas similar to the ones described earlier.

Samples of organs, including the mammary gland, with macroscopic lesions, were collected for histopathological and microbiological analysis. For the histopathology examination, specimens were fixed in $10 \%$ neutral-buffered formaldehyde. The tissues were embedded in paraffin wax, sectioned at $3 \mu \mathrm{m}$ and stained with HE (haematoxylin-eosin) and Ziehl Neelsen for acid-fast bacilli detection. For additional immunohistochemical studies in the mammary gland section, the streptavidin-biotin-peroxidase complex method was used, utilizing a commercial detection system (Ultra Vision Detection System; Lab Vision Corporation, Fremont, CA, USA), according to the manufacturer's instructions. The primary antibodies used were the following: wide-spectrum cytokeratin (Z0622, 1 : 500; Dako North America Inc., Carpinteria, CA, USA), alpha-smooth muscle actin ( $\alpha$ SMA; $1: 50$; Novocastra Laboratories Ltd., Newcastle upon Tyne, UK), Ki-67 (MIB-1, 1 : 100; Dako North America Inc.), vascular endothelial growth factor (VEGF, JH121, $1: 150$; Neomarkers, Labvision Corporation, Fremont, CA, USA), matrix metalloproteinase 2 (MMP-2, Ab-6, $1: 100$; Labvision Corporation) and MMP-9 (Ab-9, $1: 200$; Labvision Corporation), which cross-reacted with caprine tissue. Antigen retrieval was carried out in a citrate buffer ( $\mathrm{pH} 6.0)$, in a microwave oven at $750 \mathrm{~W}$, for 5 min (cytokeratin and aSMA) or three times for 5 min each (Ki-67, VEGF and MMP-2). No pretreatment was used for MMP-9 labelling. The sections were then incubated overnight at $4^{\circ} \mathrm{C}$ with the primary antibody diluted in a phosphate-buffered saline (PBS, pH 7.4, $0.01 \mathrm{~m}) .3,3^{\prime}$-diaminobenzidine tetrahydrochloride (DAB, Novocastra Laboratories Ltd.) was used as a chromogen and Mayer's haematoxylin as a counterstain. Appropriate positive and negative controls were included.

For bacteriological analysis, samples from the lung, liver, lymph nodes and mammary gland were sent frozen $\left(-20^{\circ} \mathrm{C}\right)$ to-INIAV, IP, Bacteriology Laboratory, Lisbon, where they were processed. Isolation of mycobacteria was performed according to OIE standard 


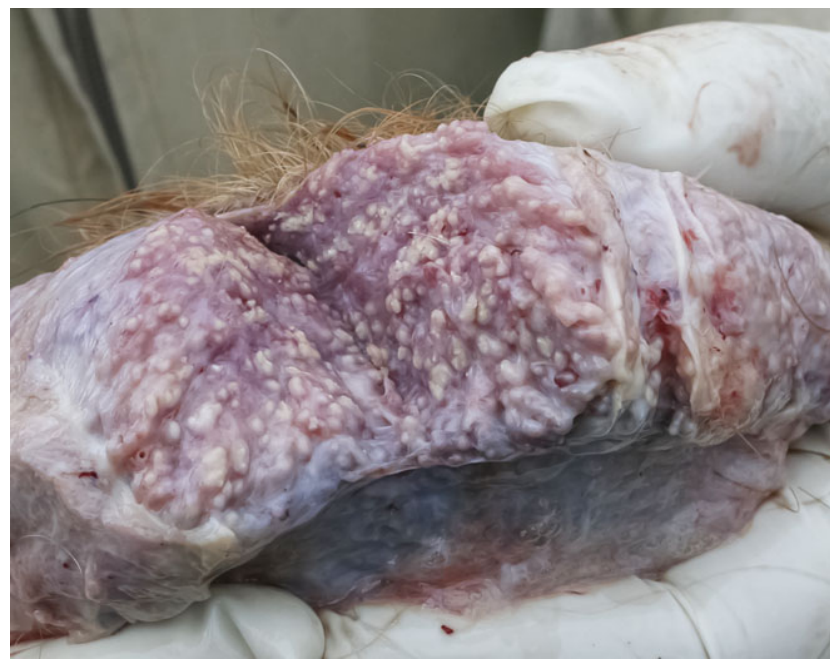

Fig. 1. Mammary gland with multifocal caseous necrosis

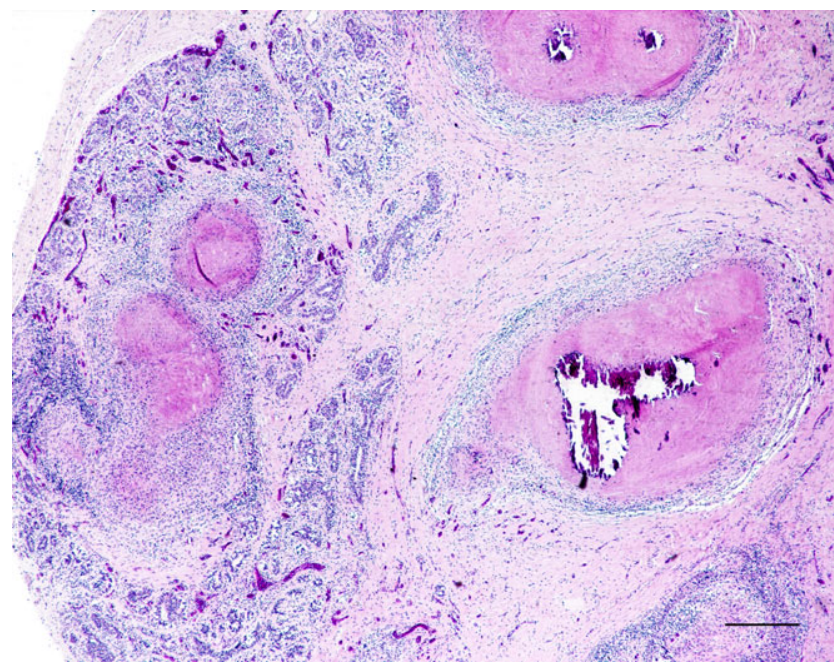

Fig. 2. Mammary tuberculous granulomas with caseous necrosis. H\&E. Scale bar $=300 \mu \mathrm{m}$

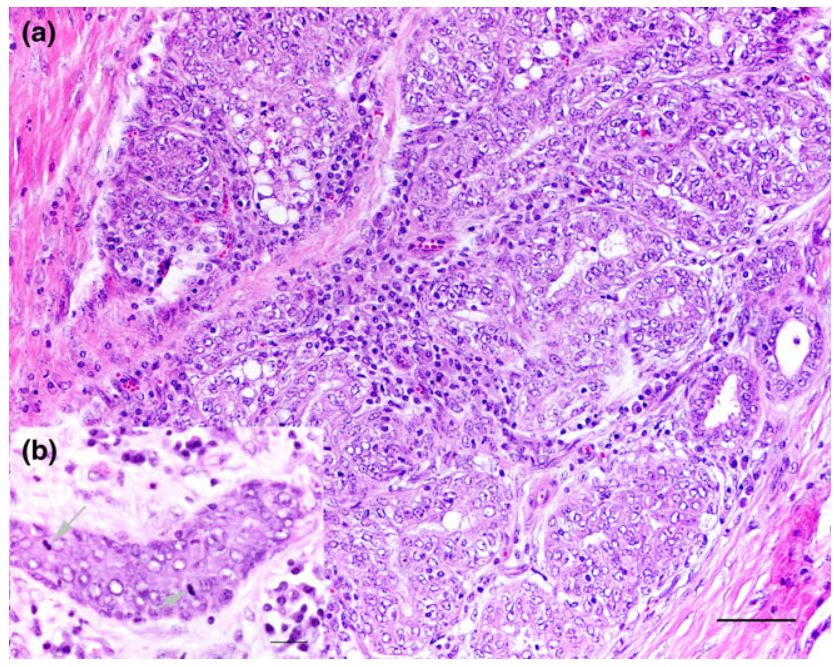

Fig. 3. (a) Mammary simple tubular carcinoma. H\&E. Scale bar $=60 \mu \mathrm{m}$. (b) Moderate anisokaryosis and evident mitotic figures (arrow). Scale bar $=20 \mu \mathrm{m}$

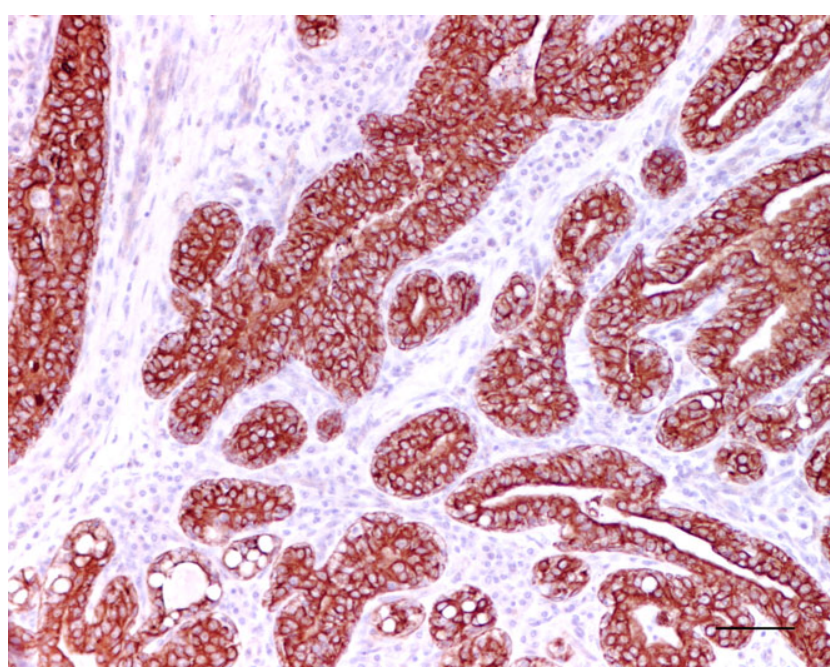

Fig. 4. Wide-spectrum cytokeratin immunostaining in epithelial tumour cells. Immunohistochemistry. Scale bar $=60 \mu \mathrm{m}$

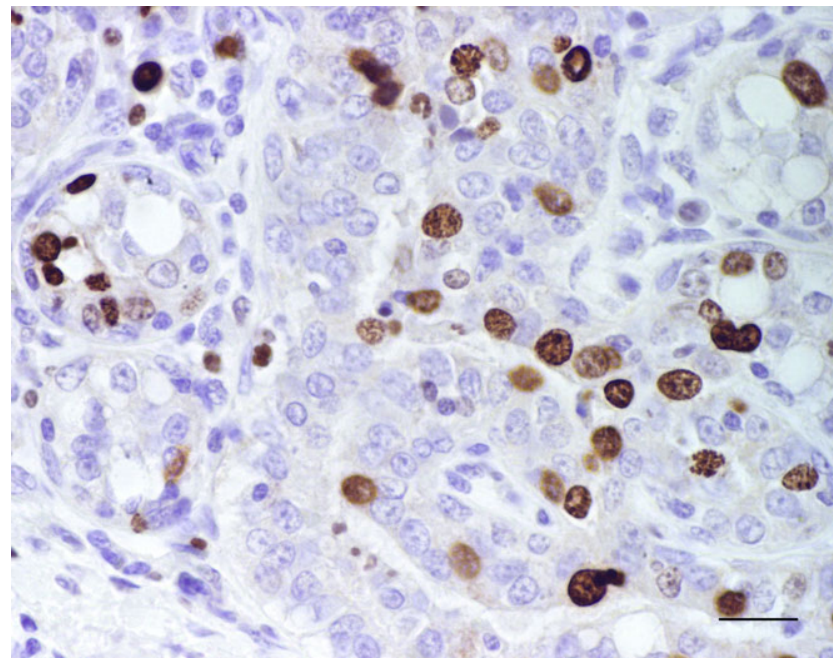

Fig. 5. Ki-67 expression in mammary tumour cells, including mitosis Immunohistochemistry. Scale bar $=30 \mu \mathrm{m}$

procedures by inoculation on BACTEC 9000 (Becton, Dickinson \& Company (BD), Franklin Lakes, NJ, USA) liquid medium and on the following solid media: Stonebrink and Löwensteinn-Jensen, with and without pyruvate. The isolates were identified by a PCR-REA system (Niemann et al. 2000) based on gyrB gene amplification and hydrolysis with RsaI and SacII restriction enzymes. Spoligotyping was performed according to Kamerbeek et al. (1997).

Histopathology revealed tuberculous granulomas in the lungs, lymph nodes, liver and spleen. The mammary gland showed a chronic granulomatous inflammation suggestive of tuberculosis. Several irregular granulomas with central areas of caseous necrosis and foci of dystrophic mineralization surrounded by epithelioid macrophages, Langhans giant cells and lymphocytes were observed. Peripherally, the granulomas presented a fibrotic capsule (Fig. 2). The presence of acid-fast bacilli within the granuloma areas was demonstrated in all of these organs. Additionally, a 


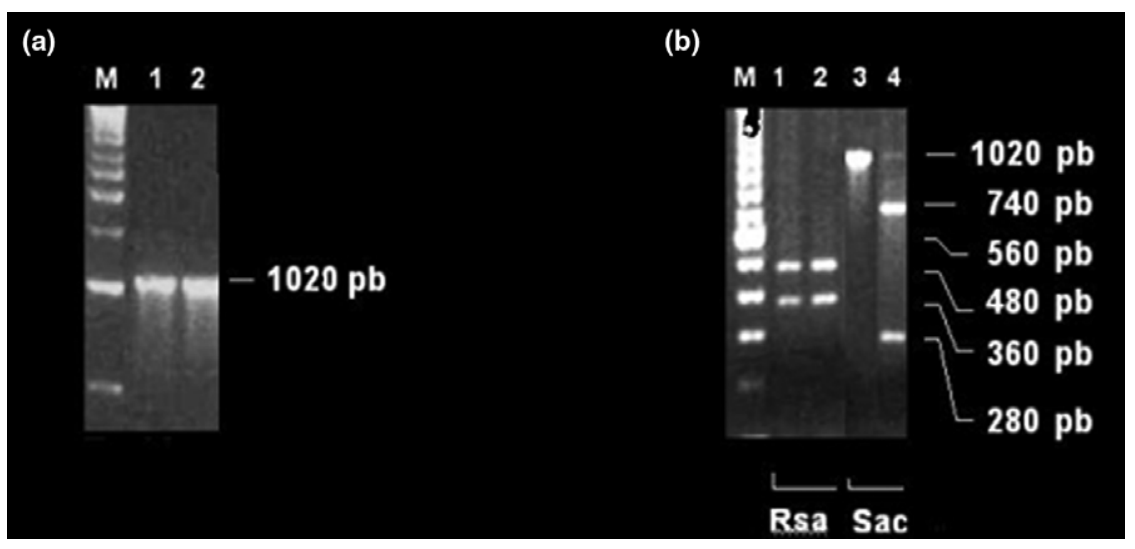

Fig. 6. PCR-REA results. (a) Specific amplified fragment obtained by PCR targeting gyrB gene. Lane $1-\mathrm{M}$. bovis BCG, Lane 2 - Mycobacterium isolate from goat. (b) Restriction endonuclease analysis of PCR product with Rsa I and Sac II enzymes. Lanes 1 and $3-\mathrm{M}$. bovis BCG, Lanes 2 and 4

Mycobacterium isolate: the two obtained fragments of 740 and $280 \mathrm{bp}$, after hydrolyses of PCR amplified fragment with SacII are specific of Mycobacterium caprae isolates

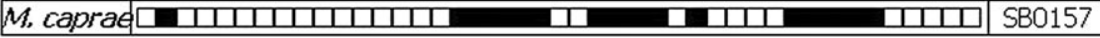

Presence of spacer $\square$ Absence of spacer Spoligotyping denomination acording to http://wmw. Mbovis. org

Fig. 7. Spoligotype pattern SB0157 of Mycobacterium caprae isolate, attributed by http://www.mbovis.org/ data base

mammary tumour, with approximately $1.5 \mathrm{~cm}$, was noted adjacent to tuberculosis lesions. The mammary tumour was unencapsulated, with ill-defined margins, with an infiltrative growth pattern, characterized by a proliferation of epithelial cells, displaying eosinophilic cytoplasm, with slight cell margins, and oval-to-round nuclei, with one or more prominent nucleolus. The neoplastic cells lining tubules with more than two layers, often with a loss of cell polarity (Fig. 3a). The intertubular stroma was fibrovascular and moderate, with mild lymphoid and plasma cells infiltration. At least 1-2 mitosis was seen in the higher power field and moderate anisokaryosis was also present (Fig. 3b). None of the other organs examined histologically contained metastases.

The presence of a distinct brown colour indicated a cytoplasmic diffuse reaction, which was noted in neoplastic cells for wide-spectrum cytokeratin (Fig. 4), but not for alpha-smooth muscle actin. The proliferative index was $15 \%$ (Fig. 5). This was calculated as the number of Ki-67-positive nucleus to the total number of neoplastic cells, counting 1000 cells, in 8-10 randomly selected homogeneous high-power fields, and expressed as the percentage of positive cells. The tumoural cells also exhibit a diffuse strong reaction for VEGF. Matrix metalloproteinases were also diffusely expressed in tumoural cells, with a moderate (MMP-2) or weak labelling intensity (MMP-9), and in stroma fibroblast. The tumour was classified as a simple tubular carcinoma.

Mycobaterium was isolated from samples and identified as M. caprae by PCR-REA (Fig. 6). The isolate was characterized by spoligotyping revealing the spoligotype pattern SB0157 (Fig. 7). This spoligotype presents the typical signature of $\mathrm{M}$. caprae (absence of spacers 1, 3-16, 28, 30-33 and 39-43) and is the most common spoligotype of $\mathrm{M}$. caprae strains isolated in Portugal (Duarte et al. 2008).

Based on the earlier observations, a granulomatous tuberculosis mastitis caused by $\mathrm{M}$. caprae and a mammary tubular simple carcinoma were diagnosed.

\section{Discussion}

In man, the simultaneous occurrence of tuberculosis and cancer is unusual and can be a problem in its diagnosis and treatment (Munjal et al. 2010; Akbulut et al. 2011).

In goats, in spite of some rare cases of mammary tuberculosis and mammary tumours reported, this is the first report, to the authors' knowledge, describing a tuberculous mastitis with simultaneous occurrence of mammary cancer.

The synchronic occurrence of granulomatous mastitis due do $M$. caprae and mammary cancer could be coincidental. However, in humans, some mechanisms are discussed to explain the close relationship between tuberculosis and several types of cancer (Javed et al. 2013; Silva et al. 2013). One hypothesis is that tuberculosis could contribute to the onset of cancer and the other hypothesis is that mammary cancer could lead to tuberculosis. Indeed, inflammation associated with infections can contribute to carcinogenesis. In human tuberculosis, inflammation and fibrosis associated with this disease can lead to lung cancer. In these pathways, inflammatory mediators and cytokines, such as the tumour necrosis factor $\alpha(\mathrm{TNF}-\alpha)$, are involved. These inflammatory mediators contribute to tumour initiation by stimulating the production of genotoxic molecules, such as nitric oxide and reactive oxygen species, that can lead to DNA damage. Additionally, TNF- $\alpha$ can promote angiogenesis and tumour-cell survival. The inflammatory process and the high fibroblast synthesis of extracellular matrix components are also involved; blockage of the lymphatic flow might increase cancer risk through the delayed clearance of activated leucocytes and the enhanced probability of metastatic cell deposition within the fibrotic area (Hussain et al. 2003; Yu et al. 2008; Vento and Lanzafame 2011). Furthermore, carcinogens concentrate preferentially in hyperactive areas and still epithelium in areas of tissue repair could be more susceptible to those carcinogenic agents (Silva et al. 2013). Given the similarities between the 
course of tuberculosis in humans and in goats (Sanchez et al. 2011), the same mechanisms of cancer induction by tuberculosis inflammatory process might have occurred in this case.

The hypothesis that mammary cancer can promote tuberculosis does not seem valid in this case because tuberculosis was already present in the herd, prior to the detection of the tumour.

Mammary lesions should always be investigated because they could be very important for the diagnosis of tuberculosis. The udder becomes involved during the dissemination of the infection to other organs as liver, kidney and spleen (Bernabé et al. 1991). An early detection of individuals/herds with tuberculosis is crucial to ensure the success of eradication programs for tuberculosis. In this case, the agent was M. caprae, spoligotype SB0157, the most common M. caprae spoligotype found in Portugal and Spain (Duarte et al. 2008). Furthermore, the transmission of tuberculosis through the milk should not be neglected, both to kids, contributing to increase the prevalence of the disease, and to men, due to the zoonotic implications of the intake of unpasteurized milk.

In this study, we also describe the occurrence of simple tubular mammary carcinoma. The diagnosis was based not only on the histological features as the predominant cell type, invasive growth, but also on their immunohistochemical profile. Positivity to cytokeratin and the absence of labelling to alpha-smooth muscle actin in tumour cells excludes a diagnosis of complex carcinoma because alpha-smooth muscle actin marks myoepithelial cells (Peña et al. 2014).

The collection of mammary gland for microbiological and histopatological examination was essential in the diagnosis of the two pathologies. Only with accurate diagnostic methods, is it possible to determine the true prevalence of tuberculosis mastitis associated with neoplastic conditions of the mammary gland, which otherwise can remain underdiagnosed.

\section{Acknowledgements}

The work was supported partially by the Strategic Research Project Pest PEst-OE/AGR/UI0772/2014 financed by the Foundation for Science and Technology (FCT).

\section{Conflict of interest}

None of the authors have any conflict of interest to declare.

\section{Author contributions}

$\mathrm{H}$ Quintas and A Mendonça participated in clinical evaluation and samples collection. I Pires and A Alves carried out the histological and immunohistochemical methods. N Alegria contributed to microbiological diagnosis procedures. A Botelho performed molecular identification and typing of Mycobacterium isolate. I Pires, $\mathrm{H}$ Quintas and A Botelho wrote the manuscript but all the authors participated also in its revision.

\section{References}

Akbulut S, Sogutcu N, Yagmur Y, 2011: Coexistence of breast cancer and tuberculosis in axillary lymph nodes: a case report and literature review. Breast Cancer Res Treat 130, 1037-1042.

Aranaz A, Cousins D, Mateos A, Dominguez L, 2003: Elevation of Mycobacterium tuberculosis subsp. caprae Aranaz et al. 1999 to species rank as Mycobacterium caprae comb. nov., sp. nov. Int J Syst Evol Microbiol 53, 1785-1789.

Bernabé A, Gómez A, Navarro A, Gómez S, Sidrach J, Menchen V, Vera A, Sierra A, 1991: Morphopathology of caprine tuberculosis II. Tuberculosis generalizada. Annales de Veterinária de Murcia 6/7, 21-29.

Cooke MM, Merrall M, 1992: Mammary adenocarcinoma and granulosa cell tumour in an aged Toggenberg goat. $\mathrm{N}$ Z Vet J 40, 31-33.

Duarte E, Domingos M, Amado A, Botelho A, 2008: Spoligotype diversity of Mycobacterium bovis and Mycobacterium caprae animal isolates. Vet Microbiol 130, 415-421.

Gutierrez M, Samper S, Gavigan JA, Garcia Marin JF, Martin C, 1995: Differentiation by molecular typing of Mycobacterium bovis strains causing tuberculosis in cattle and goats. J Clin Microbiol 33, 29532956.

Gutierrez M, Samper S, Jimenez MS, van Embden JD, Marin JF, Martin C, 1997: Identification by spoligotyping of a caprine genotype in Mycobacterium bovis strains causing human tuberculosis. J Clin Microbiol 35, 3328-3330.
Hussain SP, LJ H, CC H, 2003: Radical causes of cancer. Nat Rev Cancer 3, 276285.

Inoue M, Iwaki Y, Hua J, Hagihara M, 2012: Pulmonary mucosa-associated lymphoid tissue lymphoma coexisting with intratumoral tuberculosis. Rinsho Ketsueki 53, 1921-1925.

Javed A, Arora A, Kalayarasan R, Sakhuja P, Agarwal AK, 2013: Gallbladder cancer management impacted by coexistent tuberculosis. Trop Gastroenterol 34, 87-90.

Kamerbeek J, Schouls L, Kolk A, van Agterveld M, van Sooling D, Kuijper S, Bunschoten A, Molhuizen H, Shaw R, Goyal M, van Embden J, 1997: Simultaneous detection and strain differentiation of Mycobacterium tuberculosis for diagnosis and epidemiology. J Clin Microbiol 35, 907-914.

Kubica T, Rusch-Gerdes S, Niemann S, 2003: Mycobacterium bovis subsp. caprae caused one-third of human M. bovis-associated tuberculosis cases reported in Germany between 1999 and 2001. J Clin Microbiol 41, 3070-3077.

Löhr CV, 2013: One hundred two tumors in 100 goats (1987-2011). Vet Pathol 50, 668-675.

Mani NS, Manoj MG, Malik A, 2013: Concurrent renal tuberculosis and renal cell carcinoma: a coincidental finding. Indian J Nephrol 23, 237.

Munjal K, Jain VK, Agrawal A, Bandi PK. 2010: Co-existing tubercular axillary lymphadenitis with carcinoma breast can falsely over-stage the disease: case series. Indian J Tuberc 57, 104-107.
Niemann S, Harmsen D, Rusch-Gerdes S, Richter E, 2000: Differentiation of clinical Mycobacterium tuberculosis complex isolates by gyrBDNA sequence polymorphism analysis. J Clin Microbiol 38, 3231-3234.

Peña L, Gama A, Goldschmidt MH, Abadie J, Benazzi C, Castagnaro M, Díez L, Gärtner F, Hellmén E, Kiupel M, Millán Y, Miller MA, Nguyen F, Poli A, Sarli G, Zappulli V, Mulas JM, 2014: Canine mammary tumors: a review and consensus of standard guidelines on epithelial and myoepithelial phenotype markers, HER2, and hormone receptor assessment using immunohistochemistry. Vet Pathol 51, 127-145.

Quintas H, Reis J, Pires I, Alegria N, 2010: Tuberculosis in goats. Vet Rec 166, 437438.

Sanchez J, Tomás L, Ortega N, Buendía AJ, del Rio L, Salinas J, Bezos J, Caro MR, Navarro JA, 2011: Microscopical and immunological features of tuberculoid granulomata and cavitary pulmonary tuberculosis in naturally infected goats. J Comp Pathol 145, 107-117.

Silva DR, Valentini DF Jr, Müller AM, de Almeida CP, Dalcin Pde T, 2013: Pulmonary tuberculosis and lung cancer: simultaneous and sequential occurrence. J Bras Pneumol 39, 484-489.

Tena-Suck M, Collado-Ortiz MA, Rembao-Bojorquez D, Gestista N, Garcia-Marquez A, 2010: Coexistence between meningioma and tuberculosis: case report. J Neurooncol 99, 289-294.

Vento S, Lanzafame M, 2011: Tuberculosis and cancer: a complex and dangerous liaison. Lancet Oncol 12, 520-522. 
Wooldridge AA, Gill MS, Lemarchand T, Eilts B, Taylor HW, Otterson T, 1999: Gynecomastia and mammary gland adenocarcinoma in a Nubian buck. Can Vet $\mathbf{J}$ 40, 663-665.

Yu YY, Pinsky PF, Caporaso NE, Chatterjee $\mathrm{N}$, Baumgarten $\mathrm{M}$, Langenberg $\mathrm{P}$, Furuno JP, Lan Q, Engels EA, 2008: Lung cancer risk following detection of pulmonary scarring by chest radiography in the prostrate, lung, colorectal, and ovarian screening trial. Arch Intern Med 168, 2326-2332.

Submitted: 11 Nov 2013; Accepted: 14 Apr 2014
Author's address (for correspondence): Isabel Pires, Department of Veterinary Sciences, University of Tras-os-Montes and Alto Douro, 5000 Vila Real, Portugal. E-mail: ipires@utad.pt 